Research Article

\title{
Experimental Study of Three-Dimensional Propagation of Crack in Transparent Rock Mass
}

\author{
Zhende Zhu, ${ }^{1,2}$ Yuan Tian $\mathbb{D D}^{1,2}$ and Xinyu Liu (D) ${ }^{1,2}$ \\ ${ }^{1}$ Key Laboratory of Ministry of Education of Geomechanics and Embankment Engineering, Hohai University, \\ Nanjing 210098, China \\ ${ }^{2}$ Jiangsu Research Center Geotechnical Engineering Technology, Hohai University, Nanjing 10098, China
}

Correspondence should be addressed to Yuan Tian; yuantian424@hhu.edu.cn

Received 25 June 2021; Accepted 7 August 2021; Published 18 August 2021

Academic Editor: Jie Liu

Copyright ( $\odot 2021$ Zhende Zhu et al. This is an open access article distributed under the Creative Commons Attribution License, which permits unrestricted use, distribution, and reproduction in any medium, provided the original work is properly cited.

Three-dimensional crack propagation in a rock mass was investigated using a specifically designed material with good transparency and elastoplasticity. The material has properties that are similar to those of the nature sandstone. Hydromechanical tests were conducted to simulate pore pressure in the paper to study the influence of the angle of the primary crack and the water pressure on the mechanical stability of the rock mass. The results indicated that the water pressure accelerated the crack propagation and the failure of the samples. The influence of water pressure on initiation crack strength was not significant but had a significant impact on the peak strength. With the increase in water pressure, the crack initiation strength, penetration strength, and peak strength all decrease in varying degrees. The penetration strength did not only depend on the pore pressure but also exhibited high sensitivity to the inclination angle of the primary crack. The extended finite element method is used to simulate hydraulic fracturing. The simulation results show that the stress near the tip exhibited a cycle of energy accumulation-crack expansion-stress relaxation as the crack expanded, and this finding was consistent with Griffith's energy theory.

\section{Introduction}

Rocks contain a large number of primary joints and fractures, which are the result of long-term geological processes. The existence of joints, cracks, and other structural planes in the rock mass provides natural channels for the flow of groundwater and play a major role in underground oil and gas exploitation. The presence of high-pressure groundwater has negative effects on rock mass engineering projects. The water pressure often causes local tensile stress concentration near rock mass cracks, which results in instability and failure of the rock mass engineering.

In 1920, Griffith $[1,2]$ made important breakthroughs in theoretical and experimental research and laid the foundation for fracture mechanics of brittle materials. In 1958, Irwin [3] established the stress intensity factor (SIF) criterion, which is a crack growth criterion. The concept of the SIF provided a great breakthrough in the brittle fracture theory. Sneddon [4] established an analytical model of the induced stress around a plane with a single crack, which has become the cornerstone of subsequent studies. Hubbert and Willis [5] stated that, due to limited access to the subsurface, direct observation cannot be used to monitor the interaction between hydraulic fractures and natural fractures.

At present, considerable achievements have been made in the study of rock mass fractures and mechanical-hydraulic coupling. Research on crack propagation and fracture behavior of fractured rock masses has changed from investigating a single crack to multiple cracks and from twodimensional crack to 3D crack propagation. Waters et al. [6] and Dahi Taleghani and Lorenzo [7] believe that widely used techniques such as microseismic methods may show the effect of natural fractures on hydraulic fracture growth only qualitatively and not quantitatively. Lamont and Jessen [8] performed 70 hydraulic fracturing experiments in six different rock types using triaxial compression (up to $1140 \mathrm{psi}$ ) with different approach angles to understand the phenomenon of crossing fractures. It was found that hydraulic 
fractures appeared to cross closed preexisting fractures at all intersection angles. Daneshy [9] found that hydraulic fractures terminated when the natural fractures were open at the intersection point, and they crossed the natural fractures when they were closed. Anderson [10] showed the importance of friction on hydraulic fracture growth near unbonded rock interfaces. Cleary et al. [11] believed that the fracture energy (due to pressure) was high enough to open any fracture in any orientation, but no scheme or analysis was provided to back up this claim, and the posttreatment pressure analyses did not support this claim. Ren et al. [12] used a coupled hydromechanical numerical model to investigate the propagation path of a two-cluster perforation fracture system. 3D stress anisotropy, stress heterogeneity, and Young's modulus heterogeneity were investigated to obtain a basic understanding of the spatial path of a twocluster fracture system. Zhou et al. [13] conducted a hydraulic fracturing experiment under triaxial stress at $20^{\circ} \mathrm{C}$, $100^{\circ} \mathrm{C}, 200^{\circ} \mathrm{C}, 300^{\circ} \mathrm{C}$, and $400^{\circ} \mathrm{C}$ and analyzed the characteristics of the water pressure loading curves. Fan et al. [14-17] studied the crack propagation and damage evolution around the hole and tunnel. Liu [18] and Liu and $\mathrm{Hu}$ [19] found that the AE signals during the crack propagation in the fractured rock mass were obtained, and the mechanism of compressive shear fracture of the fractured rock mass was determined. $\mathrm{Li}$ et al. [20] used an AE instrument to detect damage and observed the failure process of prefabricated cracks in marble. The test results showed that the prefabricated crack considerably reduced the strength and the elastic modulus of the rock mass and secondary cracks formed such as wing cracks, compressor-shear cracks, and reverse wing cracks. Jian et al. [21, 22] analyzed the process of hydraulic fracturing of a fractured rock mass and the initiation and propagation of internal fractures using CT scanning. Zhu et al. [23-26] utilized scanning electron microscopy to investigate the microfracture characteristics of marble by conducted triaxial compression tests on marble samples under different confining pressures and water pressures. Li and Lv [27] selected ceramics to analyze the propagation process of a single crack under triaxial compression using real-time CT scanning. The test results showed that, under triaxial compressive stresses, the crack was initially compressed, and subsequently, the propagation of the wing crack was restricted.

In recent years, many numerical methods have been used to simulate the crack initiation and coalescence in brittle materials. These include the finite element method (FEM) or extended finite element method (XFEM) [28, 29], smoothed particle hydrodynamics [30,31], displacement discontinuity analysis (DDA) [32, 33], and particle flow code (PFC) $[34,35]$. The XFEM has all the advantages of the traditional FEM, but it is not necessary to conduct mesh division to determine defects such as existing cracks in the structure. The major advantage is that crack propagation is independent of the mesh boundaries, unlike in the CZM and other simulation methods.

Although many researchers have used CT, scanning electron microscopy, and other means to observe the evolution of cracks inside rocks, these methods do not provide immediately intuitive observation. Therefore, we used epoxy resin, a curing agent, and an accelerator to design a kind of transparent material with transparency, brittleness, and other physical properties that are close to nature rock mass. Precast cracks and water pressure guide holes are created in the sample, and a self-designed high-pressure water injection device is used to apply water pressure to the sample. The crack propagation behavior at different water pressures and the crack inclination during uniaxial loading are evaluated. Apart from the experiment of hydraulic fracturing, the research of cracks propagation has been investigated through numerical simulation as well. Comparing with the in situ test and laboratory test, the numerical simulation is an economical and practical method to simulate the failure process of jointed rock masses.

\section{Experimental}

2.1. Design of Samples Containing Cracks. In this study, the preparation of samples should be conducted under the condition of below $15^{\circ} \mathrm{C}$. Too high temperature will cause the material to react too quickly and lead to the formation of internal cracks. In the production process, add $1 \%$ isocyanate curing agent in curing stage. After stirring for 1-2 minutes, add $0.3 \%$ accelerant to stir until even. The accelerated curing agent is shown in Figure 1. The curing agent and the accelerator cannot be added at the same time, and the addition of stirring at the same time will lead to uneven reaction between curing agent and accelerator, resulting in poor transparency of the sample. Pour the mixed resin into the prepared mold. In this test, it was found that the release agent could easily lead to uneven surface of the sample, so the release agent was abandoned in this test, and a layer of BOPP original film was applied inside the mold. The original film of BOPP was smooth, and there was no reaction during the resin solidification process. There will be bubbles in the stirring process, after the mixing of this ratio, the bubbles will slowly rise to the surface and release the inner bubbles at the initial stage of the reaction.

The open cracks fabricated in this test consist of mica sheet and transparent plastic ring. The upper and lower fracture planes are composed of mica pieces. The thickness of elliptical mica sheet is $0.2 \mathrm{~mm}$, and the edges around the elliptic mica pieces are connected by transparent plastic rings. Transparent plastic ring can not only prevent the resin from leaking into the crack during pouring, but also visually see the water pressure inside the crack when pressurizing. The thickness of the produced opening crack is $0.3 \mathrm{~mm}$, and the inlet hole is reserved on the crack surface to be connected with the aqueduct. The crack angle is measured and fixed when the crack is bonded to the aqueduct. The aqueduct adopts transparent high-pressure water pipe, which is characterized by good compressibility and pressure-bearing property, which can prevent the annular deformation of the pipe to produce lateral force on the sample during water pressure addition. After the cracks are fixed in the mold, the resin is poured into the mold. After 24 hours of solidification at $15^{\circ} \mathrm{C}$, the mold can be released. Then, the solidified samples were oven-dried, baked, and frozen repeatedly to 


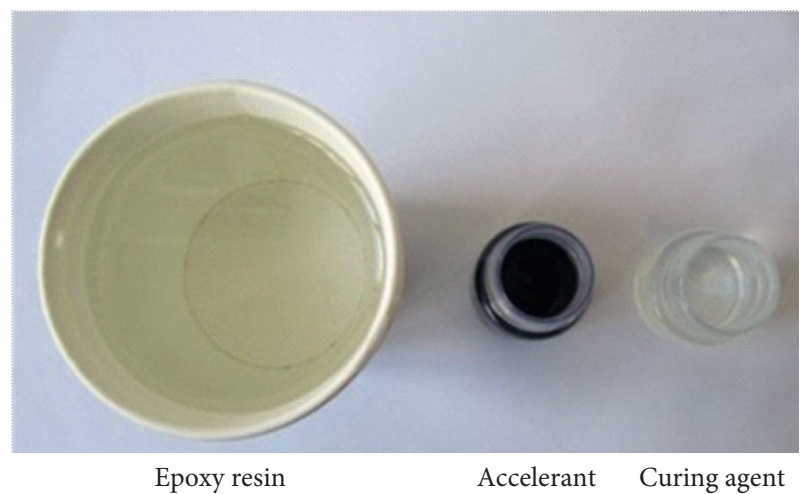

FIgURE 1: Epoxy resin and additives.

obtain better brittleness and material properties similar to that of rock. The oven and freezer used in this test are shown in Figures 1 and 2. Low temperature can make the sample more brittle. The long and short axes of the elliptical crack are $2 \mathrm{a}$ and $2 \mathrm{~b}$, respectively. The prefabricated crack inclination angle is $\alpha$. A diagram and photo of the specimen are shown in Figures 3 and 4 . This test mainly studies the propagation of cracks. The pipeline problem is a singlefactor controllable problem. The existence of the pipeline is still chosen to be preserved in the absence of water pressure. According to the explanation of elastic mechanics, the mechanical influence will be reduced to a small value at twice the diameter of the water-passing pipe. In this paper, the ratio of pipe diameter to crack length can reach 11, reaching a weakening ratio. The common substance in natural rock formations is mica. Choosing to use mica is to restore the state of natural rocks as much as possible. The transparent plastic ring is selected in the experiment to observe the realtime situation of liquid injected into the crack, and the selected plastic ring has high flexibility and low toughness, so as to weaken the existence of the plastic ring as much as possible.

The material parameters of the transparent rock in this test and sandstone are shown in Table 1, and the uniaxial compression stress-strain curves of the transparent rock sample and the nature sandstone sample are shown in Figure 5. The physical properties of natural rocks and transparent materials are shown in Table 1 . The natural sandstone is taken from a deep sandstone underground in Zaozhuang coal mine in Shandong Province, China.

2.2. Test Method and Procedure. Testing study is carried on the equipment RMT-150B. As shown in Figure 6, RMT150B rock mechanics test system is specially designed for testing the mechanical properties of engineering materials such as rock and concrete. This instrument can preset the test steps and be completed automatically by the computer. The experimenter can also intervene in the test process and change the control mode and test parameters. After the test, the computer system can present the stress-strain curve, elastic modulus, Poisson's ratio, and other results of the sample. The high-pressure water injection equipment is selfdesigned and used with the servo testing machine. The water
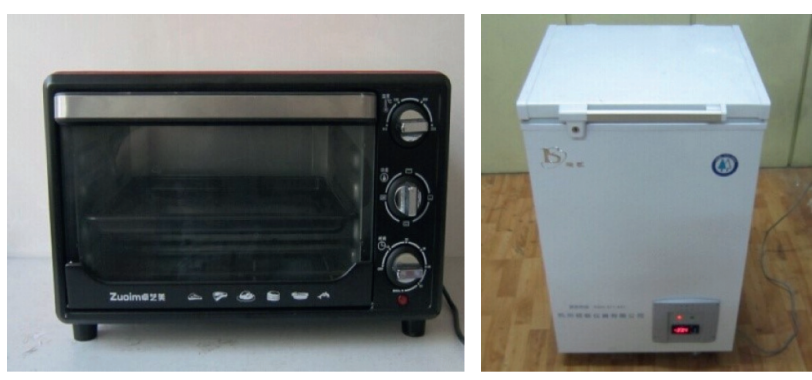

FIgURE 2: The oven and freezer in test.

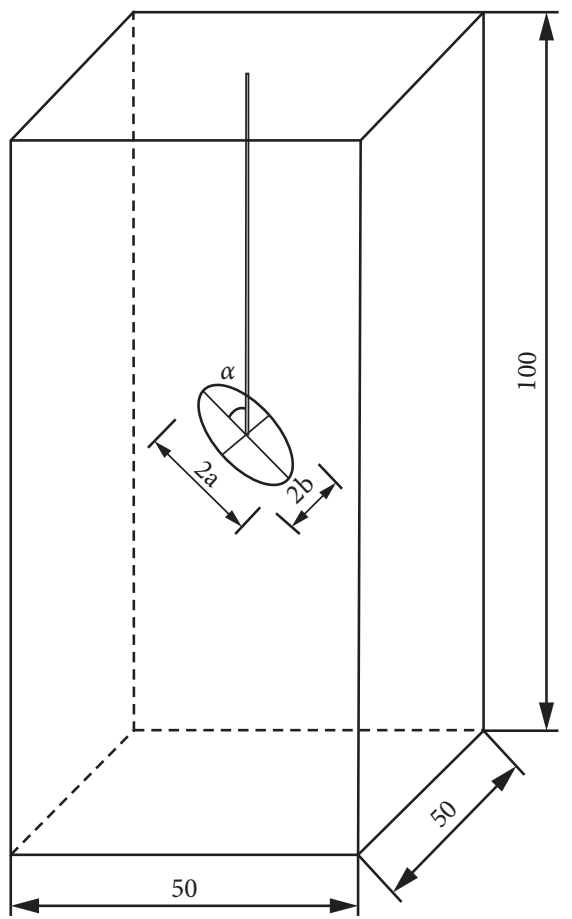

Figure 3: Sketch of specimen.

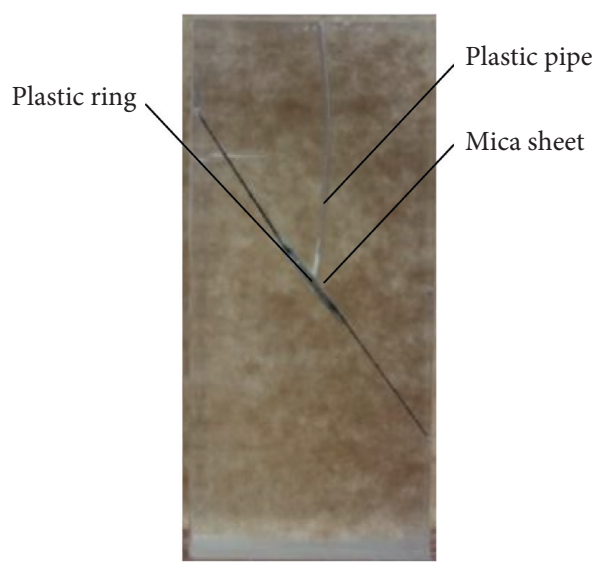

Figure 4: The finished specimen.

injection equipment consists of three parts: a modified hydraulic Jack, an oil-water conversion device, and a rigid loading cushion block (Figures 7 and 8 ). The hydraulic Jack 
TABLE 1: Mechanical parameters of the transparent rock and sandstone.

\begin{tabular}{lccccc}
\hline Category & Density $\left(\mathrm{g} / \mathrm{cm}^{3}\right)$ & Elasticity modulus $(\mathrm{GPa})$ & Compressive strength $(\mathrm{MPa})$ & Tensile strength $(\mathrm{MPa})$ & Fragility \\
\hline Transparent rock & 1.8 & 6.8 & 116.5 & 18 & 6.5 \\
Nature sandstone & 2.51 & 9.2 & 109.6 & 16 & 6.85 \\
\hline
\end{tabular}

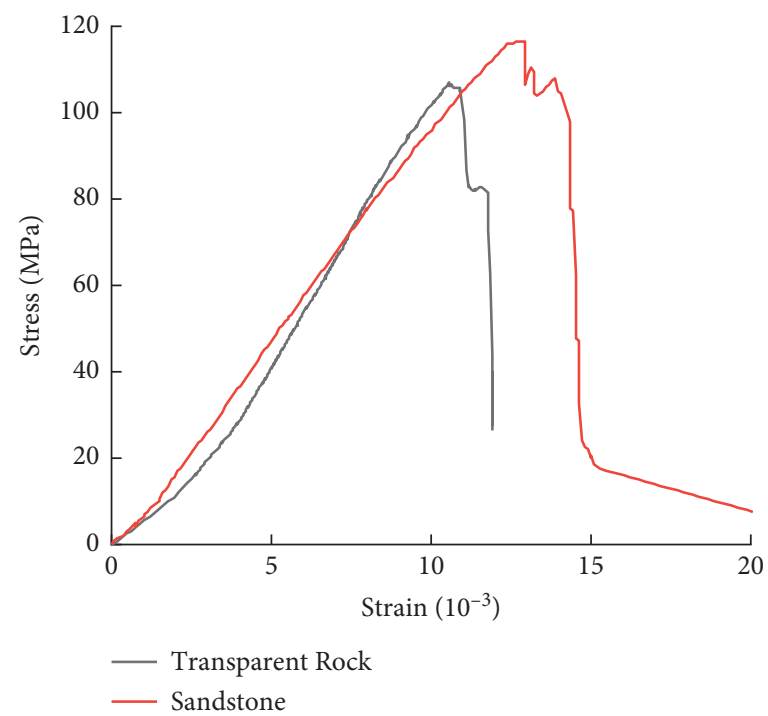

FiguRE 5: Stress-strain curves of the intact transparent rock sample and nature sandstone sample.
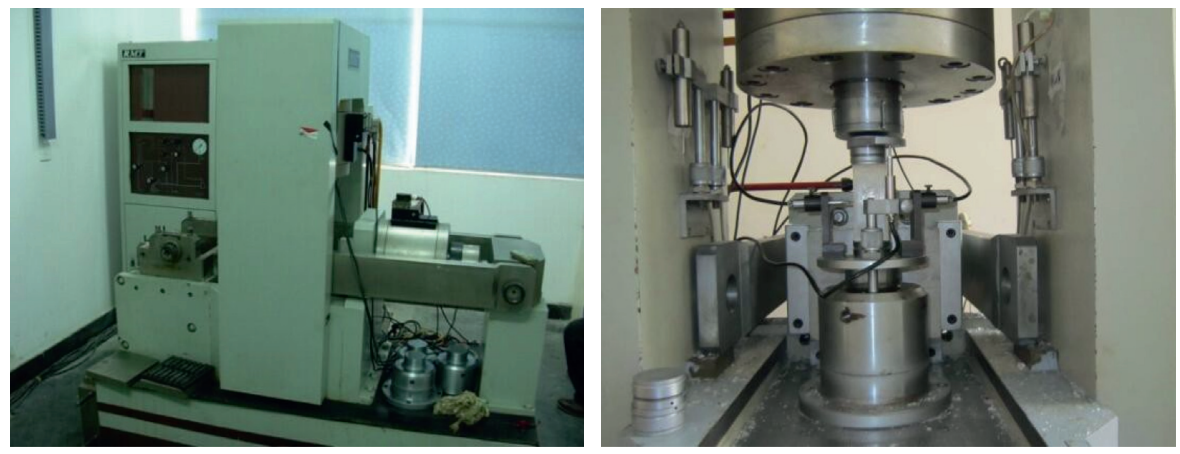

Figure 6: Rock mechanics rigidity servo testing system.

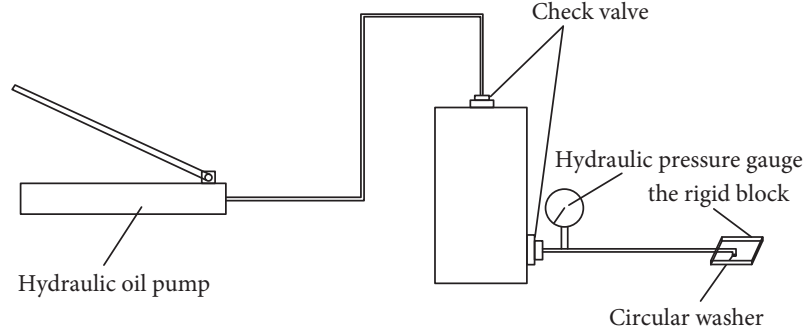

Figure 7: Sketch of water injection device.

uses 15\# antiwear hydraulic oil and it generates maximum oil pressure of $70 \mathrm{MPa}$.

In this test, when installing the sample, the water outlet of the rigid cushion block has to be aligned with the sample inlet pipe. A round rubber washer is added between the

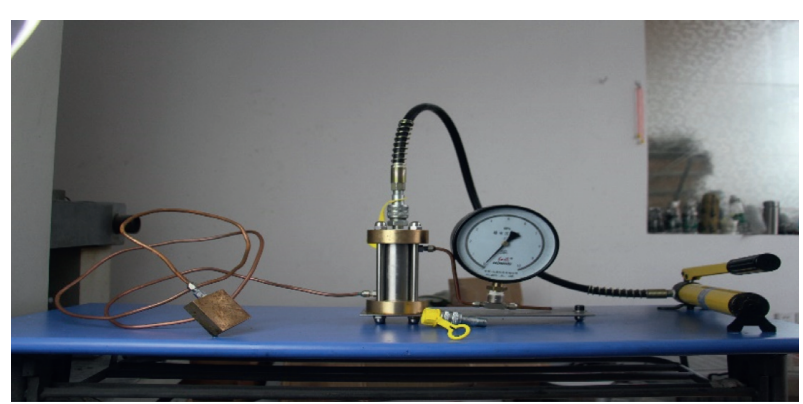

Figure 8: Water injection device.

outlet of rigid cushion block and the inlet pipe to ensure a tight connection. After the sample and water injection equipment are assembled, the servo test machine is used for 
axial loading. Displacement control is used to create a load of $5 \mathrm{MPa}-10 \mathrm{MPa}$, in which the sealing property is satisfied, and no plastic damage is caused to the specimen by this time. A hydraulic pump is used to apply water pressure to the crack. After the water pressure has been applied, an axial load is applied to the specimen using the servohydraulic test machine; the axial loading rate of $0.005 \mathrm{~mm} / \mathrm{s}$ is controlled by the axial displacement sensor. During the test, a highspeed camera was used to capture the dynamic expansion of the cracks.

\section{Experimental Results}

3.1. Changes in Stress and Strain with Water Pressure. In this section, the standard sample with $\alpha=45^{\circ}$ and $2 \mathrm{a}=2 \mathrm{~cm}$ of the prefabricated crack is used as an example to illustrate the crack propagation behavior. The fracture propagation process under $0-6 \mathrm{MPa}$ water pressure was studied. The stress-strain curves of the specimens subjected to hydraulic pressures of 0-6 MPa are shown in Figure 9. According to the stress-strain curve, the existence of water pressure obviously reduces the maximum bearing capacity of rock mass. The failure strength of the sample without hydraulic fracture is about $81.7 \mathrm{MPa}$. With the increase of water pressure of $1 \mathrm{MPa}$, the failure strength of the sample decreases by about $10 \%$. It was observed that the initiation strength of prefabricated cracks did not change obviously with the increase of water pressure. It can be seen from the test that the water pressure has little effect on the initiation cracking strength and elastic modulus of the sample, but it has great influence on the subsequent crack growth.

3.2. Crack Growth Process under Different Water Pressures. In this section, samples with no water pressure and different water pressures are selected for fracture expansion analysis and comparison. The influence of water pressure on the mechanism of crack propagation was analyzed by visually observing the experimental phenomena.

3.2.1. $0 M P a$. Development of wrapped wing crack: as shown in Figure 10(a), when the axial stress of the sample without water pressure reaches the about $30 \%$ of peak strength, the upper and lower ends of the long axis of the elliptic prefabricated crack produce wing cracks at the same time. The initial propagation crack length is about $30 \%$ of the prefabricated crack. At this time, only the crack tip had local plastic failure, and the whole specimen was still in the elastic deformation stage.

In the absence of water pressure, the wing cracks grow rapidly as the stress reaches $50 \%$ of the peak strength. At this time, the secondary crack propagates along the edge of the prefabricated crack and forms an envelope, and the direction continues to turn towards direction of the axial load. When the length of the wing crack is close to the length of the precast crack, the wing crack ceases to extend, and petalshaped cracks appear in the area between the secondary crack and the precast crack, as shown in Figure 10(b). When the stress of the sample not exposed to water pressure

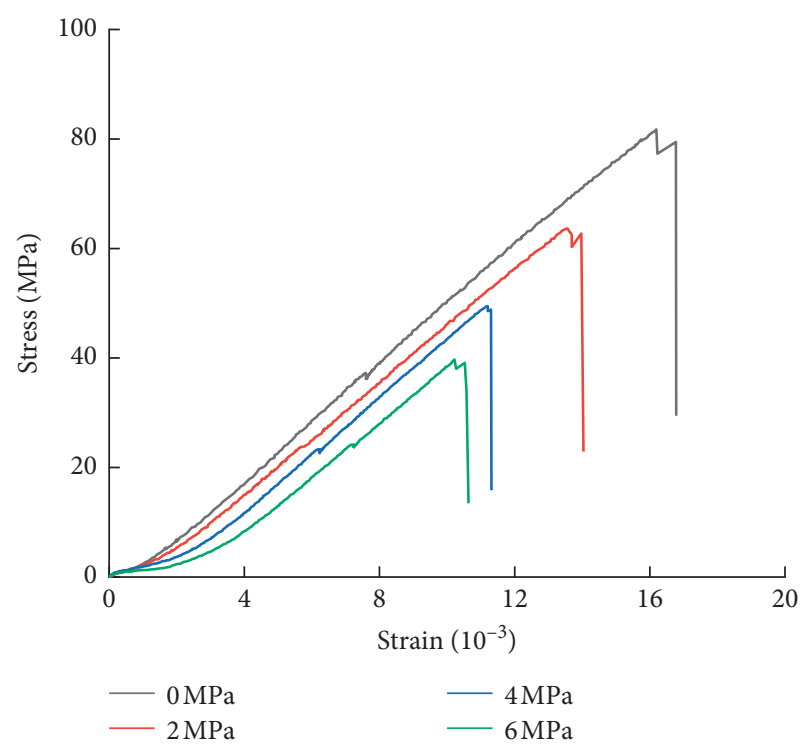

FIGURE 9: Stress-strain curve of the precast fracture specimen with a $45^{\circ}$ dip angle.

reaches a peak strength of about $65 \%$, new petal-shaped cracks continue to appear in the area between the secondary and prefabricated cracks. Then, the crack expands rapidly in the vertical direction, forming large vertical splitting cracks, and crackling sounds are heard, as shown in Figure 10(c). At this time, the crack propagation of the sample was complex, but it still did not penetrate, and the samples have not failed and have not lost their bearing capacity completely.

In all cracking propagation, secondary cracks appear at the crack tip first, and the secondary crack propagation direction turns to the direction of maximum principal stress in the medium term. Finally, the crack propagation runs through the sample in the vertical direction.

3.2.2. $2 \mathrm{MPa}$. When a water pressure of $2 \mathrm{MPa}$ is applied to the prefabricated crack of the sample, the appearance of the secondary crack under the influence of water pressure is basically the same as that without water pressure, and the crack propagation angle is also basically the same. The secondary cracks show a partial inky color, as shown in Figures 11(a) and 11(b), indicating that the cracks are not fully penetrated. The macroscopic shape of the crack did not change with the increase of axial pressure, but the ink color was full of secondary cracks, indicating that the effective area of secondary cracks was increasing. Due to the existence of water pressure, the appearance of cracks is not symmetrical cracking at the same time. In the test, the appearance of secondary cracks at the tip did not always appear at the same time. Different from the nonhydraulic cracks, there are no petal-like cracks in the secondary cracks, and the cracks grow relatively slowly in the axial direction, as shown in Figure 11(c). With the increase of the axial load, the cracks propagate in the axial and horizontal directions at the same time, but when the crack length is close to the preformed crack, the crack propagates rapidly until it penetrates the sample, as shown in Figures 11(d) and 11(e). 


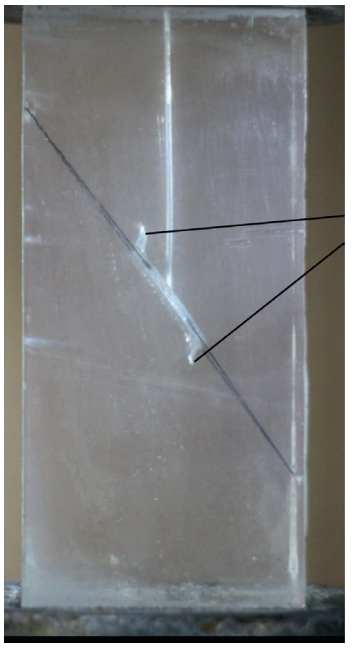

(a)

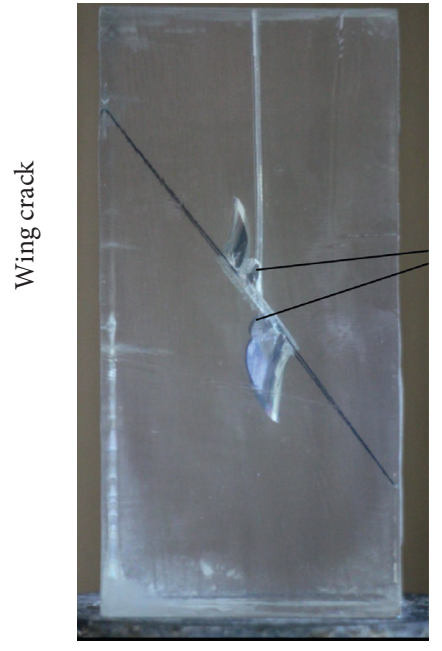

(b)

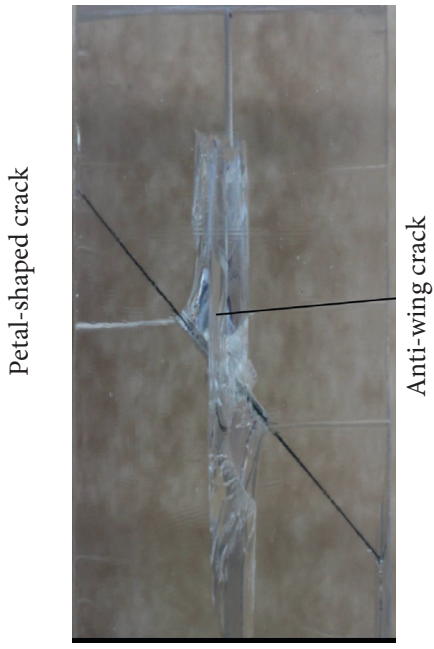

(c)

Figure 10: Crack propagation process under $0 \mathrm{MPa}$ water pressure. (a) $\sigma=30 \% \sigma_{\max }$. (b) $\sigma=65 \% \sigma_{\max }$. (c) $\sigma=90 \% \sigma_{\text {max. }}$

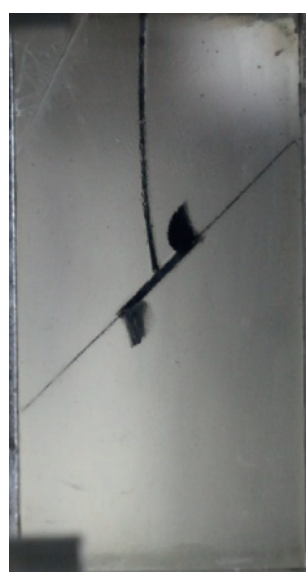

(a)

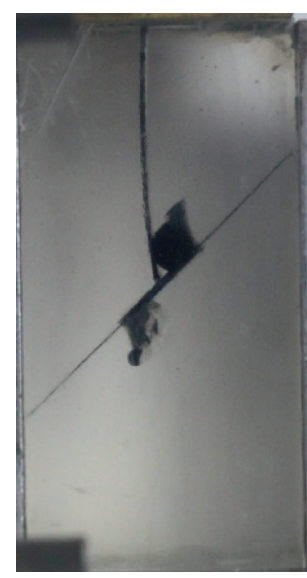

(b)

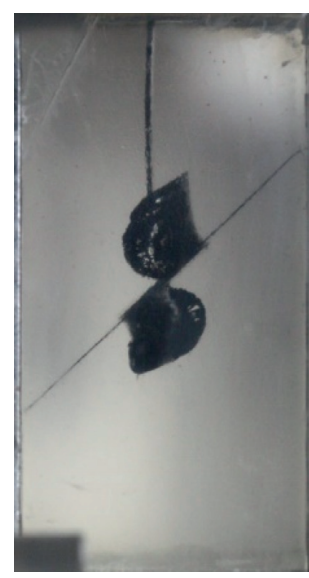

(c)

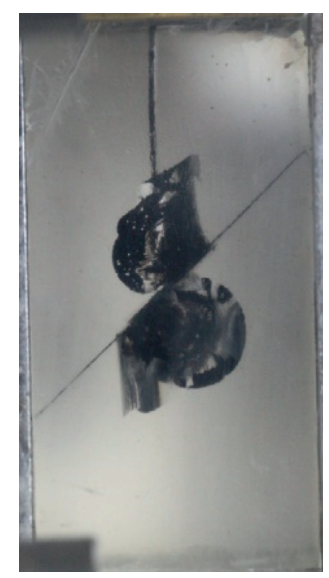

(d)

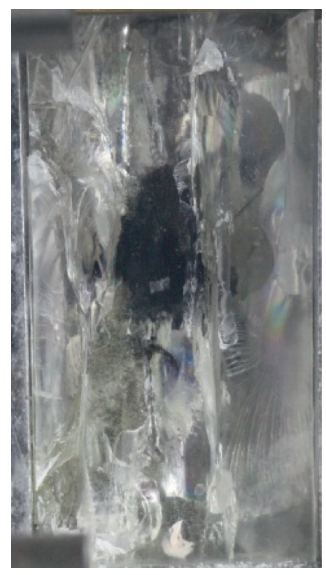

(e)

FiguRE 11: Crack propagation process under $2 \mathrm{MPa}$ water pressure. (a) $\sigma=35 \% \sigma_{\max }$. (b) $\sigma=45 \% \sigma_{\max }$. (c) $\sigma=50 \% \sigma_{\max }$. (d) $\sigma=60 \% \sigma_{\max }$. (e) $\sigma=95 \% \sigma_{\max }$.

3.2.3. $4 \mathrm{MPa}$. Under the influence of water pressure of $4 \mathrm{MPa}$, as shown in Figure 12(a), the secondary crack appears at the peak strength of $32 \%$. The strength value is slightly lower than that of the initial crack of the sample not exposed to water pressure. The secondary wing crack is full of black ink, indicating that the flow channel is unobstructed, and water can enter the secondary crack, thereby exerting generate water pressure on the secondary crack. However, the shape of the wing crack is similar in both samples, indicating that pore pressure has little influence on the angle or shape of the initiation secondary crack. As shown in Figure 12(b), unlike the $2 \mathrm{MPa}$ water pressure, the water pressure occupies all the secondary cracks due to the larger water pressure. When the length of the secondary crack reached 1.5 times the length of the prefabricated crack, an antiwing crack appeared, and the crack began to expand laterally until the lateral penetrating liquid leaked out. However, the rock mass does not completely lose its bearing capacity when the liquid leaked out, and the lateral penetration stress is about $90 \%$ of the peak stress, as shown in Figures 12(c) and 12(d).

In the presence of pore pressure, secondary crack propagation occurs between $40 \%$ and $60 \%$ of peak strength, and it went through three or four expansions. The vertical expansion approaches the axial load direction gradually. The shape of the secondary fracture is similar to that in the sample not exposed to water pressure, but the fracture expansion rate is faster. However, the enveloping crack is not obvious, and it is mainly vertical and lateral propagation, and petal-like crack did not appear.

3.2.4. $6 \mathrm{MPa}$. When the fracture water pressure increases to $6 \mathrm{MPa}$, secondary cracks appear at $55 \% \sigma_{\max }$, as shown in Figure 13(a). After the secondary cracks appear, both the 


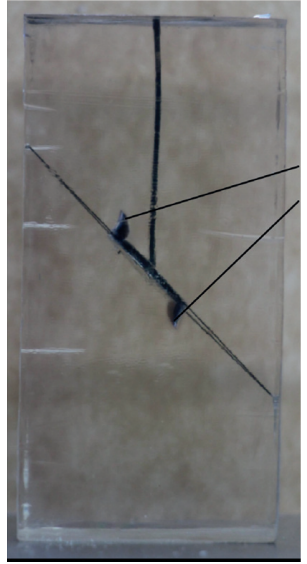

(a)

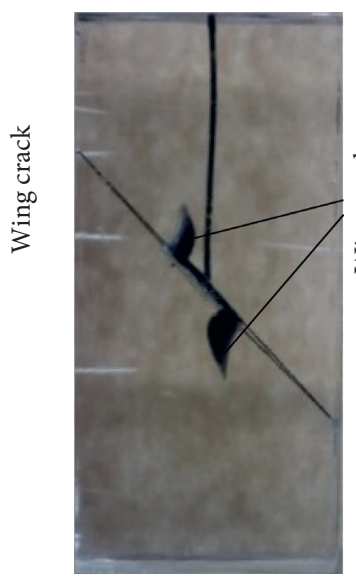

(b)

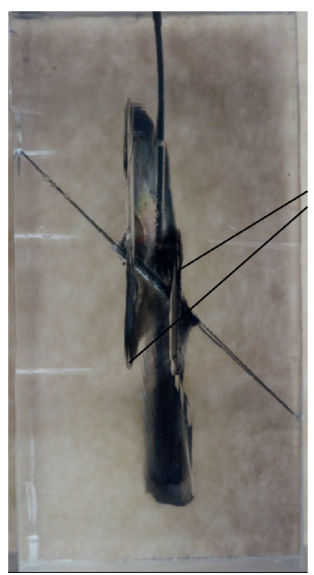

(c)

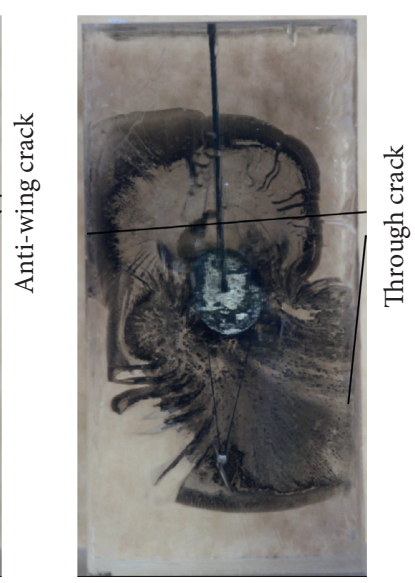

(d)

FiguRE 12: Crack propagation process under $4 \mathrm{MPa}$ water pressure. (a) $\sigma=32 \% \sigma_{\max }$. (b) $\sigma=45 \% \sigma_{\max }$. (c) $\sigma=50 \% \sigma_{\max }$. (d) $\sigma=90 \% \sigma_{\max }$.

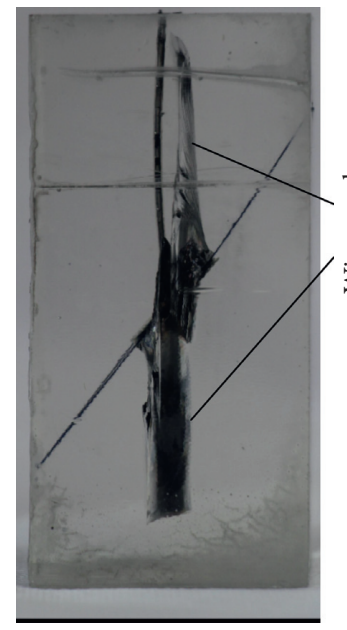

(a)

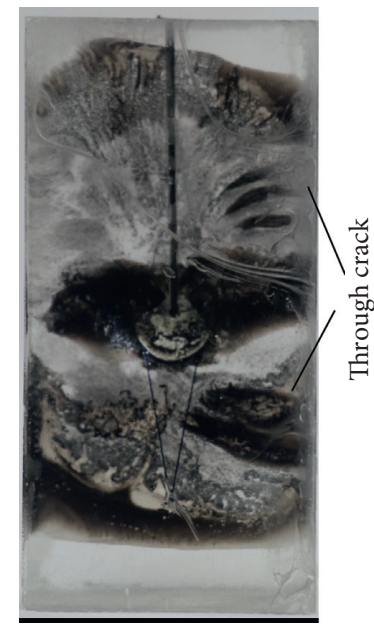

(b)

FIGURE 13: Crack propagation process under $6 \mathrm{MPa}$ water pressure. (a) $\sigma=55 \% \sigma_{\max }$. (b) $\sigma=85 \% \sigma_{\max }$.

vertical and lateral directions rapidly expand until the sample penetrates, and then the liquid seeps out. Due to the existence of high-water pressure, the crack growth of the upper and lower wings is extremely unstable and not symmetric, as shown in Figure 13(b). However, the sample did not lose its bearing capacity at this time, and the bearing capacity thereafter has nothing to do with water pressure value.

\section{Influence of Hydraulic on Mechanical Properties}

4.1. The Influence of Different Water Pressure Values on Stress and Strain. The sample with prefabricated crack angle of $45^{\circ}$ was used to analyze the initiation strength, penetration strength, and peak strength under different water pressures. According to the experiment, the initiation stress of the prefabricated cracks does not change significantly with the increase in water pressure. As shown in Figure 14, the initiation stress of the prefabricated cracks does not change

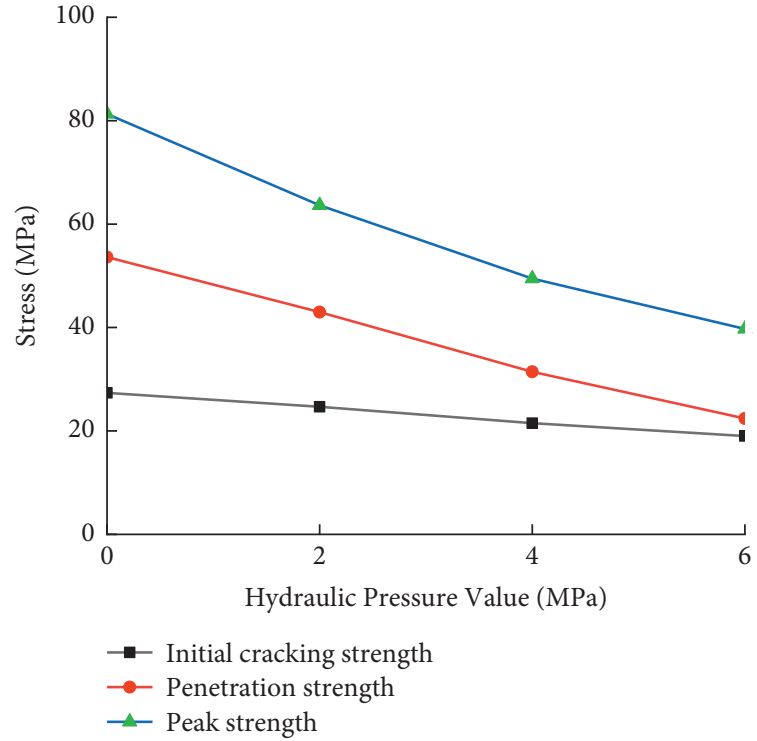

FIGURE 14: Stress varies with water pressure. 
significantly with the increase in water pressure, but once the secondary crack appears, the influence of the water pressure increases significantly. With the increase in the water pressure, the penetration strength also decreases. When the water pressure value reaches $4 \mathrm{MPa}$, the secondary crack will quickly expand when it reaches the length of the prefabricated crack. This situation is very dangerous in practical engineering because the occurrence of water leakage events often leads to instability of the engineering rock mass, often causing sudden disasters.

\subsection{The Influence of Different Water Pressure Values on Strain.} Based on the study of the effect of water pressure on stress, the process law of water pressure on the failure process of the specimen can be studied through the study and analysis of the strain of the specimen. As shown in Figure 15, the effect of water pressure on the crack initiation strain is not significant. With the increase of water pressure, the crack initiation strain does not fluctuate significantly. The water pressure has a great influence on the through strain. With the appearance of water pressure, the through strain decreases greatly. When the water pressure reaches $6 \mathrm{MPa}$, the sample will run through in a short time after crack initiation. However, the penetration of the specimen does not lead to the loss of the bearing capacity of the specimen. From the peak strain, it can be seen that the existence of water pressure leads to the decrease of the peak strain, but it is because the water pressure leads to the penetration of the specimen in advance, which affects the peak bearing capacity of the specimen.

4.3. Crack Propagation Stress with Different Dip Angles. Naturally occurring cracks have various configurations, and the inclination angle of the cracks has considerable influence on the stability of rocks. Rocks containing cracks with different inclination angles often exhibit different mechanical properties. The dip angles of the prefabricated cracks in the transparent samples were $15^{\circ}, 30^{\circ}, 45^{\circ}$, and $60^{\circ}$, and $2 \mathrm{MPa}$ of water pressure was applied. The changes in the strength of the sample for different dip angles of the crack are shown in Figure 16. The results show that the penetration strength is the most sensitive to the inclination angle. The crack initiation strength and penetration strength decrease with an increase in the inclination angle. When the inclination angle is $60^{\circ}$, the fracture initiation strength is close to the penetration strength, indicating that the larger the inclination angle is, the more easily the crack is spreading. But the crack initiation angle is not different from that without water pressure, indicating that water pressure has little effect on crack initiation angle.

4.4. Variation of Crack Length under Different Water Pressures. The length of fissure was analyzed by experiment. For the analysis of fracture length in this test, samples at dip angle of $45^{\circ}$ were selected for analysis. In order to avoid the influence of different primary fracture length, the secondary fracture length is denoted by the multiple of prefabricated

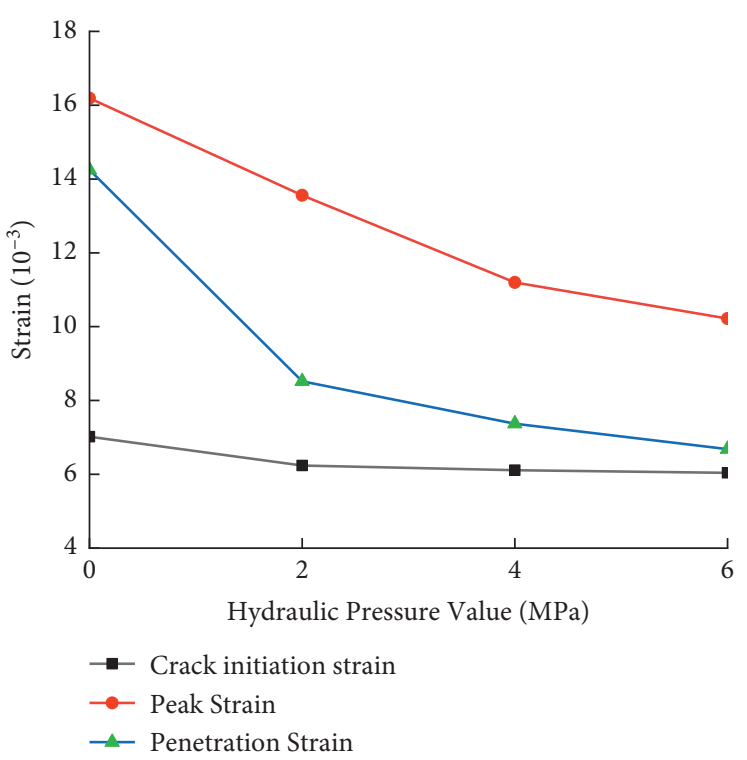

Figure 15: Strain varies with water pressure.

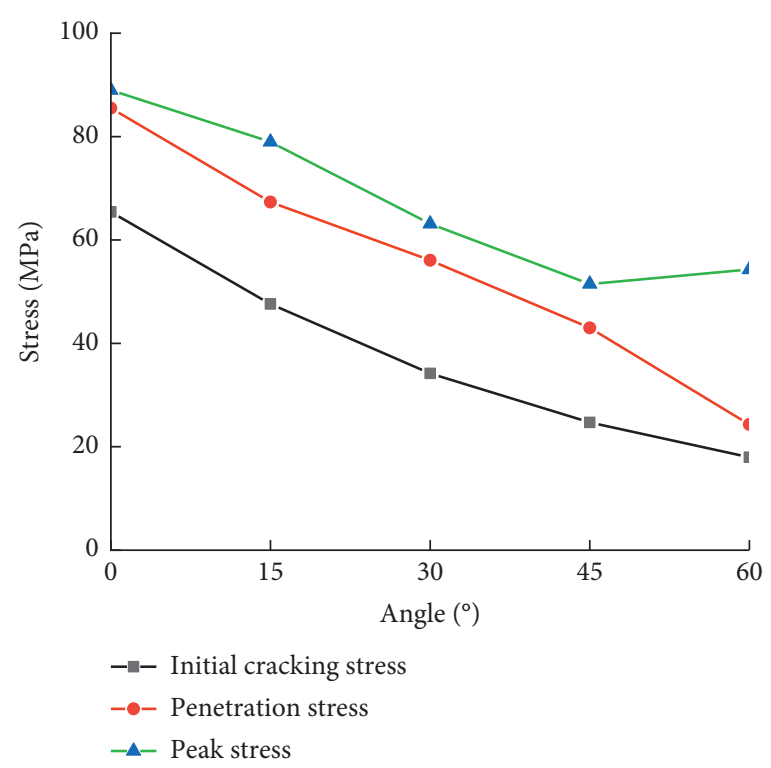

FIGURE 16: Strength changes for different preexisting crack angles.

fracture. As Figure 17 shows, the influence of water pressure on rock mass is not only reflected in stress, but also on crack propagation speed. The existence of water pressure accelerates the crack propagation process. According to the curve, the slope of the crack without water pressure is relatively gentle. With the increase of water pressure, the slope of the curve increases gradually. It can be seen from the experiment that when the water pressure is lower than $2 \mathrm{MPa}$, the crack propagation process is close to that without water pressure. When the water pressure is increased to $4 \mathrm{MPa}$, the expansion speed is obviously accelerated. When the water pressure reaches $6 \mathrm{MPa}$, the crack grows rapidly, and water inrush is easy to occur in the project. 


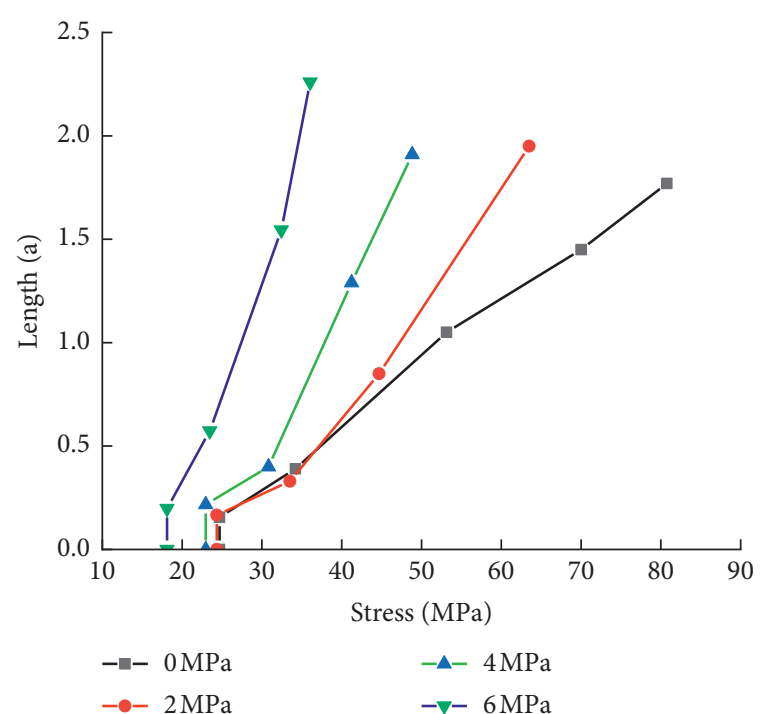

FIGURE 17: The fracture length changes in different water pressure.

Through the different propagation lengths of the cracks at different times, the propagation speed of the cracks under different water pressures can be obtained. We use the average value of the slope of the propagation length of each period in Figure 17 as the crack propagation rate. We compare the crack growth rate at $0 \mathrm{MPa}$ water pressure as 1 , as shown in Figure 18. From the results, it can be seen that the crack growth rate increases steadily when the water pressure is from 0 to $4 \mathrm{MPa}$, and at $6 \mathrm{MPa}$, the crack growth rate increases significantly.

\section{Numerical Simulation}

The existence of water pressure has a great influence on the expansion of the fracture, but the stress at the tip of the fracture is difficult to monitor in time. In this paper, the extended finite element method (XFEM) in simulation software ABAQUS is used to simulate the laboratory experiment. In the process of modeling, the corresponding model parameters are shown in Table 2. The intermediate point of crack was selected as the injection point in the test. In order to conform to the natural rock, the guide flume reserved in the test was ignored in the numerical simulation. The actual engineering size of the model is adopted, the length and width of the model are $50 \mathrm{~m}$, the crack length is $1 \mathrm{~m}$, and the dip angle is $45^{\circ}$ in the middle of the model. With the boundary fixed on both sides of the model, the crackdown on the surface of the contact is not defined. In order to prevent the difficulty in calculating caused by stress surge, the amplitude curve of hydraulic injection was defined, the injection was accelerated in the first ten seconds, and the model was compressed after applying the pressure. As in the laboratory tests, uniaxial compression USES displacement control and the control speed is $0.005 \mathrm{~mm} / \mathrm{s}$. Considering that crack propagation is a brittle fracture process occurring at the crack tip, the critical stress is selected as the crack propagation criterion in this study to determine the critical point of the rock mass stress fracture and the trend during

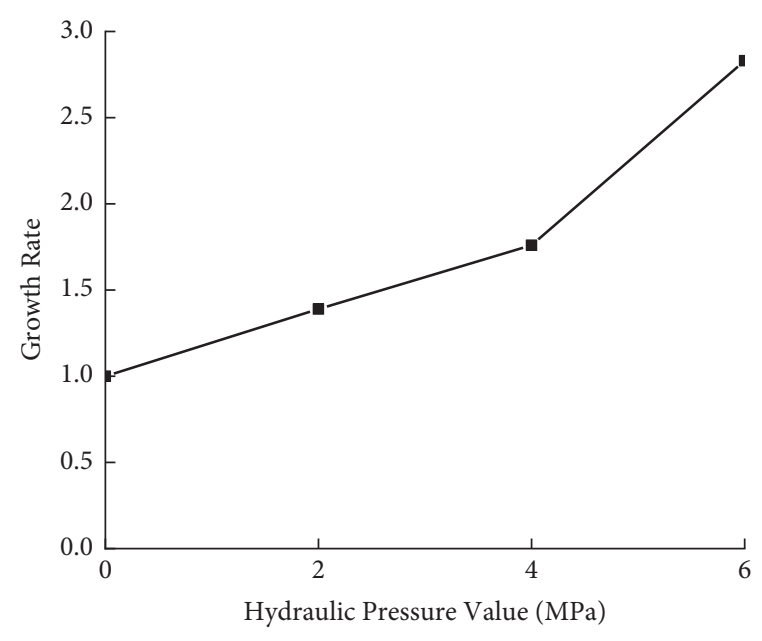

FIGURE 18: Crack growth rate under different water pressures.

TABLE 2: Simulation model parameters.

\begin{tabular}{lc}
\hline Parameter & Values \\
\hline Elasticity modulus (GPa) & 15 \\
Poisson's ratio & 0.25 \\
Tensile strength (MPa) & 6 \\
Permeability coefficient (m/s) & $1 e-7$ \\
Filtration coefficient (m/Pas) & $1 e-14$ \\
Fracturing fluid viscosity (Pas) & 0.001 \\
\hline
\end{tabular}

the propagation. The fracture failure is controlled by maximum normal stress criterion, and the damage evolution is controlled by displacement failure. A viscosity regularization coefficient was added to the model to increase its stability.

The model in this section uses a $45^{\circ}$ precrack inclination angle. It can be known through numerical simulation that the water pressure and tip stress in the crack and the change with time are studied through the set injection rate. As shown in Figure 19, as the cracks expand, the water pressure in the cracks fluctuates sharply. Especially, before the cracks propagate, a large amount of energy is accumulated before the cracks propagate. A large amount of energy is released at the initial stage of crack propagation. After the energy is released, the liquid enters the new crack surface, and the water pressure decreases instantaneously. When the crack propagation turns to the vertical stress direction, the water pressure required for the crack propagation stress is stable until the water pressure drops linearly when it penetrates. The change of the stress at the crack tip is similar to that of water pressure. As shown in Figure 20, during the crack propagation process, the tip stress at the initial stage of crack propagation is more complex and exhibits larger fluctuations. The relevant theoretical content of Griffith is as follows and readded to the thesis.

Girffith (1921) did not directly consider the stress at the crack tip, using the strain energy density around the crack obtained by Inglis (1913) to do the full-field integration to obtain the elastic potential energy formula 


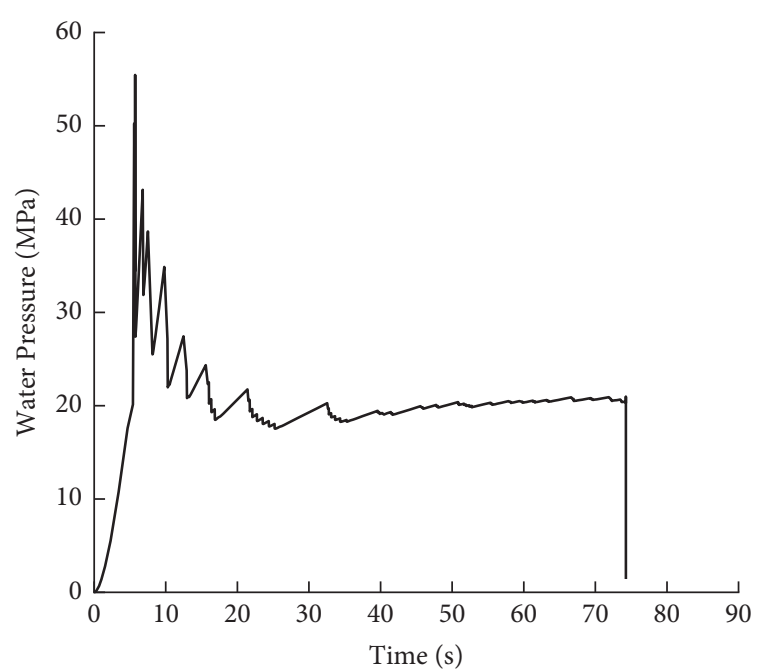

FIgURE 19: Change of water pressure in fractures with time.

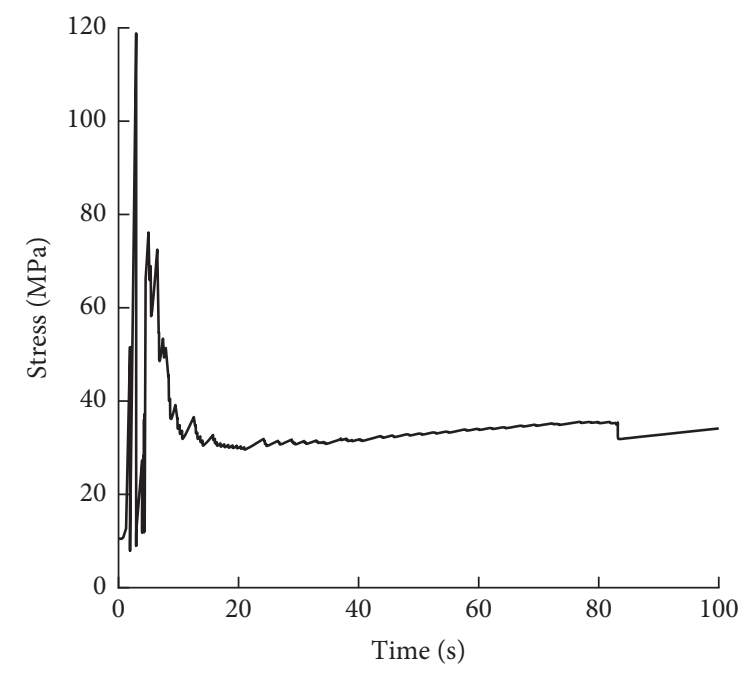

FIgUre 20: Change of tip stress with time.

$$
W_{c}=\frac{\pi \sigma^{2} a^{2}}{E^{\prime}}
$$

where $W_{c}$ is the elastic potential energy, and when a new crack occurs, the increased surface energy is

$$
S=4 a \Gamma,
$$

where $\Gamma$ is the surface energy per unit area and a is the crack propagation length. If the release rate of elastic potential energy is greater than or equal to the increase rate of surface energy, the crack growth condition is obtained as

$$
\frac{\mathrm{d} w_{c}}{\mathrm{~d} a}=\frac{\mathrm{d} S}{\mathrm{~d} a} .
$$

The critical stress is obtained by substituting formulae (1) and (2).

$$
\sigma_{g}=\sqrt{\frac{2 E \Gamma}{\pi a\left(1-v^{2}\right)}}
$$

In the formula, $E, \Gamma, v$ are material constants, so $\sigma_{g} \cdot \sqrt{a}$ is a constant.

In the simulation, when the crack tip stress $\sigma_{g}$ reaches a certain value, the crack cracks. When the time is after $20 \mathrm{~s}$, as shown in Figure 20, $\sigma_{g}$ fluctuates slightly between 30 and $35 \mathrm{MPa}$ at this time. It is consistent with the conclusion that $\sigma_{g}$ will be cracked in Griffith's conclusion.

\section{Discussion}

Because of the existence of water pressure, crack propagation is controlled not only by axial load, but also by the coupling effect of axial load and water pressure. It is known from the test that the water pressure has little effect on the initial crack but has a great influence on the propagation of the secondary crack in the middle and later stages. Due to the normal pressure of water pressure on the crack surface, more transverse propagation of crack occurs. In addition, the existence of liquid weakens the friction between the upper and lower surfaces of the crack, which leads to the acceleration of crack propagation and makes the sample penetrate earlier. The penetration of the sample is only the leakage of liquid, and there is no collapse failure of the whole sample, so the penetration is always before the peak stress, and the rock mass still has a certain bearing capacity after penetration. From the experiment and numerical simulation, it can be seen that the crack propagation occurs several times continuously, each crack propagation is accompanied by stress relaxation, and some small fluctuations can be seen in the stress-strain curve. At the later stage, when the crack propagation direction turns to the vertical direction, the stress at the tip of the prefabricated crack shows an obvious cycle of stress concentration-crack propagation-stress release-stress concentration.

\section{Conclusions}

Experiments and simulations were conducted to investigate the $3 \mathrm{D}$ propagation of fractures in a transparent rock mass. The following conclusions were drawn:

(1) The initial crack stress of the samples was similar in the presence and the absence of pore water pressure, and the stress and strain of the rock mass were similar prior to cracking. The crack propagation rate was faster in the samples with pore water pressure.

(2) Petal-shaped cracks were observed in the samples exposed to water pressure, and the cracks were more prone to expand and penetrate laterally. When the water pressure is lower than $2 \mathrm{MPa}$, the crack propagation process is close to that without water pressure. When the water pressure is increased to $4 \mathrm{MPa}$, the expansion speed is obviously accelerated. When the water pressure reaches $6 \mathrm{MPa}$, the crack grows rapidly, and water inrush is easy to occur in the project. The existence of water pressure makes the crack propagate more along the crack periphery and more laterally. With the same crack length, the effective area of crack propagation is more. The 
existence of water pressure reduces the symmetry of crack propagation and increases the instability of crack propagation.

(3) With the increase in water pressure, the crack initiation strength, penetration strength, and peak strength decreased. However, the water pressure had a relatively small impact on the crack initiation strength and the largest impact on the penetration stress. Due to the influence of the water pressure, the crack penetrated the sample soon after crack initiation. The higher the water pressure, the faster the penetration rate. At a water pressure value of $6 \mathrm{MPa}$, the lateral penetration of the sample occurred almost at the same time as the crack initiation.

(4) The penetration strength did not only depend on the pore water pressure, but also exhibited high sensitivity to the inclination angle of the primary crack. With the increase in the inclination angle, the crack initiation stress and penetration stress decreased, and the inclination angle had the largest influence on the penetration strength. The peak strength reached the minimum at an angle of $45^{\circ}$, and the penetration of the rock mass after fracture initiation occurred fastest at an inclination angle of $60^{\circ}$.

(5) In the early stage of loading, the stress was concentrated around the prefabricated crack, and as the secondary crack extended, the stress concentration was at the tip of the secondary crack. The stress near the tip exhibited a cycle of energy accumulation-crack expansion-stress relaxation as the crack expanded; this finding was consistent with Griffith's energy theory.

\section{Data Availability}

The data used to support the findings of this study are available from the corresponding author upon request.

\section{Conflicts of Interest}

The authors declare that there are no conflicts of interest regarding the publication of this study.

\section{Acknowledgments}

This research work was partially carried out with financial support from the National Natural Science Foundation of China (NSFC, Grant no. 51878249), the Natural Science Foundation of Jiangsu Province (no. BK20161508), and The Postgraduate Research and Practice Innovation Program of Jiangsu Province (2018B661X14).

\section{References}

[1] A. A. Griffith, "The phenomena of ruptures and flow in solids," Philosophical Transactions, vol. 221, pp. 163-198, 1920.

[2] A. A. Griffith, "The theory of rupture," in Proceedings of the 1st International.Congress for.Applied.Mechanics, p. a221, Delft, Netherland, April 1924.
[3] G. R. Irwin, "Elasticity and plasticity/elastizität und plastizität," in Handbuch der Physik VI, S. Flugge, Ed., Springer-Verlag, Berlin, Germany, 1958.

[4] I. N. Sneddon, "III. Finite Hankel transforms," The London, Edinburgh, and Dublin Philosophical Magazine and Journal of Science, vol. 37, no. 264, pp. 17-25, 1946.

[5] M. K. Hubbert and D. G. Willis, "Mechanics of hydraulic fracturing," Transactions of the AIME, vol. 210, no. 1, pp. 153-168, 1957.

[6] G. Waters, J. Heinze, R. Jackson, A. Ketter, J. Daniels, and D. Bentley, "Use of horizontal well image tools to optimize barnett shale reservoir exploitation," in Proceedings of the SPE 103202, Presented at the SPE Annual Technical Conference, San Antonio, TX, USA, September 2006.

[7] A. Dahi Taleghani and J. M. Lorenzo, "An Alternative interpretation of microseismic events during hydraulic fracturing," in Proceedings of the SPE 140468-PP, Presentation At The Spe Hydraulic Fracturing Technology Conference And Exhibition Held In The Woodlands, Woodlands, TX, USA, Januray 2011.

[8] N. Lamont and F. Jessen, "The effects of existing fractures in rocks on the extension of hydraulic fractures," Journal of Petroleum Technology, vol. 15, pp. 203-209, 1963.

[9] A. A. Daneshy, "Hydraulic fracture propagation in the presence of planes of weakness," Society of Petroleum Engineers of AIME, vol. 4852, 1974.

[10] G. D. Anderson, "Effects of friction on hydraulic fracture growth near unbounded interfaces in rocks," SPE Journal, vol. 21, pp. 21-29, 1981.

[11] M. P. Cleary, C. A. Wright, and T. B. Wright, "Experimental and modeling evidence for major changes in hydraulic fracturing design and field procedures," in Proceedings of the Society Petroleum Engineering Gas Technology Symposium, pp. 131-146, Houston, TX, USA, January 1991.

[12] X. Ren, L. Zhou, H. Li, and Y. Lu, "A three-dimensional numerical investigation of the propagation path of a twocluster fracture system in horizontal wells," Journal of Petroleum Science and Engineering, vol. 173, pp. 1222-1235, 2019.

[13] C. Zhou, Z. Wan, Y. Zhang, and G. Bin, "Experimental study on hydraulic fracturing of granite under thermal shock," Geothermics, vol. 71, pp. 146-155, 2018.

[14] X. Fan, X. Jiang, Y. Liu, H. Lin, K. Li, and Z. He, "Local stress distribution and evolution surrounding flaw and opening within rock block under uniaxial compression," Theoretical and Applied Fracture Mechanics, vol. 112, Article ID 102914, 2021.

[15] X. Fan, Z. Yang, and K. Li, "Effects of the lining structure on mechanical and fracturing behaviors of four-arc shaped tunnels in a jointed rock mass under uniaxial compression," Theoretical and Applied Fracture Mechanics, vol. 112, 2021.

[16] X. Fan, K. Li, H. Lai, Q. Zhao, and Z. Sun, "Experimental and numerical study of the failure behavior of intermittent rock joints subjected to direct shear load," Advances in Civil Engineering, vol. 2018, no. 5, 19 pages, Article ID 4294501, 2018.

[17] H. Chen, X. Fan, H. Lai, Y. Xie, and Z. He, "Experimental and numerical study of granite blocks containing two side flaws and a tunnel-shaped opening," Theoretical and Applied Fracture Mechanics, vol. 104, Article ID 102394, 2019.

[18] D. Liu, Study on Compression-Shear Fracture and Strength Characteristics of Discontinuous Jointed Rock Mas, Chongqing Jianzhu University, Chongqing, China, 1993.

[19] D. Liu and B. Hu, "Study on acoustic emission characteristics of fractured rock under compression," Chinese Journal of 
Underground Space and Engineering, vol. 18, no. 4, pp. 210215, 1998.

[20] Y. Li, Y. Wang, L. Chen, F. Yu, and L. Li, "Experimental research on pre-existing cracks in marble under compression," Chinese Journal of Geotechnical Engineering, vol. 42, no. 1, pp. 120-124, 2004.

[21] H. Jian, S. Li, W. Zhu, and L. Qi, "CT analyses of brittle materials under hydraulic Pressure and uniaxial compression," Rock and Soil Mechanics, vol. 5, pp. 587-591, 2002.

[22] H. Jian, W. Zhu, S. Li, and L. Qi, "A preliminary CT real-time test to simulate hydraulic fracturing of jointed rock mass," Chinese Journal of Rock Mechanics and Engineering, vol. 11, pp. 1655-1662, 2002.

[23] Z. Zhu and J. Sun, "Coupling analysis model of seepage field and damage field of fractured rock mass and its engineering application," Journal of Yangtze River Scientific Research Institute, vol. 16, no. 5, pp. 22-27, 1999.

[24] Z. Zhu, W. Xu, and A. Zhang, "Mechanism analysis and testing study on damage and fracture of brittle rock," Chinese Journal of Rock Mechanics and Engineering, vol. 22, no. 9, pp. 1411-1416, 2003.

[25] Z. Zhu, Y. Zhang, and C. Wang, "Study on microcosmic mechanics for brittle-ductile transition of marble," Journal of China Coal Society, vol. 30, no. 1, pp. 31-35, 2005.

[26] Z. Zhu, Y. Zhang, and W. Xu, "Experimental studies and microcosmic analysis on marble rupture under high confining pressure and high hydraulic pressure," Chinese Journal of Rock Mechanics and Engineering, vol. 24, no. 1, pp. 44-51, 2005.

[27] Y. Li and H. Lv, "CT real-time scanning tests on single crack propagation under triaxial compression," Chinese Journal of Rock Mechanics and Engineering, vol. 29, no. 2, pp. 289-296, 2010.

[28] N. Moës and T. Belytschko, "Extended finite element method for cohesive crack growth," Computer Methods in Applied Mechanics and Engineering, vol. 69, 2002.

[29] P. Areias, D. Dias-Da-Costa, J. Alfaiate, and E. N. Brito Santos Julio, "Arbitrary bi-dimensional finite strain cohesive crack propagation," Computational Mechanics, vol. 45, no. 1, pp. 61-75, 2009.

[30] R. Pramanik and D. Deb, "SPH procedures for modeling multiple intersecting discontinuities in geomaterial," International Journal for Numerical and Analytical Methods in Geomechanics, vol. 39, no. 4, pp. 343-367, 2015.

[31] S. R. Beissel, C. A. Gerlach, and G. R. Johnson, "Hypervelocity impact computations with finite elements and meshfree particles," International Journal of Impact Engineering, vol. 33, no. 1/12, pp. 80-90, 2006.

[32] Y. Ning, J. Yang, X. An, and G. Ma, "Modelling rock fracturing and blast-induced rock mass failure via advanced discretisation within the discontinuous deformation analysis framework," Computers and Geotechnics, vol. 38, no. 1, pp. 40-49, 2011.

[33] Y. J. Ning, X. M. An, and G. W. Ma, "Footwall slope stability analysis with the numerical manifold method," International Journal of Rock Mechanics \& Mining ences, vol. 48, no. 6, pp. 964-975, 2011.

[34] R. H. Cao, P. Cao, H. Lin, C. Z. Pu, and K. Ou, "Mechanical behavior of brittle rock-like specimens with pre-existing fissures under uniaxial loading: experimental studies and particle mechanics approach," Rock Mechanics and Rock Engineering, vol. 49, no. 3, pp. 763-783, 2016.

[35] C. Cheng, X. Chen, and S. Zhang, "Multi-peak deformation behavior of jointed rock mass under uniaxial compression: insight from particle flow modeling," Engineering Geology, vol. 213, pp. 25-45, 2016. 